\title{
Social Studies Teacher-Athletic Coaches' Experiences Coping With Role Conflict
}

\author{
Caroline Conner \\ Kennesaw State University \\ Chara Haeussler Bohan \\ Georgia State University
}

\begin{abstract}
The current study provides insight into the experiences of the most common content area teacher-coaches: social studies teacher-coaches. Substantial research findings support the idea that occupying the dual role of teacher-coach may lead to role conflict, role overload, and burnout in teacher-coaches. The purpose of the study is to illuminate the unique stressors associated with occupying the dual role of social studies teacher and athletic coach (SSTC) simultaneously, and to discover ways in which SSTCs manage such conflict. Through a case study of three football SSTCs in the southeastern United States, we explored participants' experiences with role conflict, role overload, and burnout and investigated coping strategies utilized to manage stress. We conducted a series of interviews with the three SSTCs and administered the Maslach Burnout Inventory-Educators' Survey. Results indicate that participants experienced high levels of role conflict and overload; however, through a strong commitment to both roles, community support, and personal coping mechanisms, SSTCs were able to avoid burnout.
\end{abstract}

Keywords: social studies, teacher-coach, role conflict, role overload, burnout

\section{Introduction}

The popularity of school sponsored athletics has grown since the mid-20th century as has the demand for coaches at the elementary through collegiate level (National Association for Sport and Physical Education, 2008). In fact, since Title IX legislation passed in 1972, there has been a shortage of highly qualified physical education (PE) teacher-coaches. Increasingly, coaching is not confined to PE teachers, as more and more teachers of content area disciplines (English, math, science, and social studies) are hired to coach. Indeed, Camiré, Rocchi, and Kendellen (2017) found that $60 \%$ of secondary coaches were non-PE teacher-coaches who had little formal preparation in coaching prior to entering the field. Overwhelmingly, these non-PE coaches hail from social studies departments (A. Brown \& Sieben, 2013; Stacy, 2014). In a national study, Miller, Lutz, Shim, Fredenburg, and Miller (2006) found that social studies teachers accounted for $29.8 \%$ of high school coaches, second only to PE teachers (36.1\%). In a more recent study conducted in Texas, Rodgers (2013) found that $30 \%$ of football coaches also identified as social studies teachers. Moreover, social studies teachers accounted for the highest percentage of content area teacher-coaches: The next highest percentage was math teacher-coaches at $12 \%$. Furthermore, several researchers (A. Brown, 2012b; Richards, Templin, Levesque-Bristol, \& Blankenship, 2014) found that content area teachercoaches experienced higher levels of role conflict and subsequently, more burnout than PE teacher-

We want to thank the high school coaches who dedicate long hours to students. 
coaches. Literature on role conflict and burnout in the most common content area teacher-coaches (social studies), however, is scarce.

The current study is derived from a larger comprehensive investigation of SSTCs (Conner, 2014). We explored the unique experiences of the SSTC through a multiple-case study of three football SSTCs in a large school district in the southeastern United States. The purpose of this study is to illuminate the unique stressors associated with occupying the dual role of social studies teacher and athletic coach simultaneously and to discover ways in which SSTCs specifically manage role conflict. We focused on challenges that SSTCs faced in balancing dual roles and coping strategies to deal with burnout. The research question under investigation is this: What are social studies teacher-coaches' experiences with role conflict, role overload, and burnout?

\section{Literature Review}

\section{Social Studies Teacher-Coaches}

Despite the prevalence of SSTCs, researchers have largely ignored them. A. Brown and Sieben (2013) found that social science candidates have a significantly higher interest in coaching than do teacher candidates in English language arts, math, and foreign language. Similarly, findings of Chiodo, Martin, and Rowan (2002) suggested that social studies preservice teachers were interested in coaching significantly more than preservice teachers in other core disciplines. Social studies preservice teachers also believed that coaching was the most important activity to secure a teaching position. Moreover, social studies teachers were more likely to be assigned coaching duties even if they expressed no desire to coach (Weller, 2002).

Not only are social studies teachers frequently coaches, but they are often perceived to be ineffective teachers (A. Brown, 2012b; Egalite, Bowen, \& Trivett, 2015; Rodgers, 2013). In fact, Shuttlesworth and Edgington (2005) created a teaching manual to be distributed to history teachers in Texas that used football jargon and strategies to provide advice on how to teach history. The existence of such a manual implies that social studies faculty members care more about coaching than teaching and need pedagogical support. The evidence to prove this assumption, however, is virtually nonexistent. Fouts (1989) and Van Deraa and Schug (1993) conducted replicative studies comparing the effectiveness of SSTCs to social studies teachers who did not coach. Using the Classroom Environment Scale, they assessed students' perceptions of their classroom environments. The Classroom Environment Scale measured the classroom climate with a specific focus on four dimensions: relationship, personal development, system maintenance, and system change/innovation. They found slightly different results on the innovation indicator, but each study also determined that on the majority of indicators, no significant differences existed between the perceived effectiveness of SSTCs and noncoaches. Although these studies are dated, they are the only two research articles that measured the perceived effectiveness of SSTCs compared to noncoaches.

\section{Role Conflict, Role Strain, and Burnout}

Although the research specific to SSTCs is limited, the research on PE teacher-coaches is abundant. Research largely conducted in the fields of health, sport, PE, and kinesiology suggested that those who teach academics and coach athletics simultaneously often experience heightened levels of role conflict (A. Brown, 2012b; Ha, Hums, \& Greenwell, 2011; Konukman et al., 2010; Richards \& Templin, 2012; Ryan, 2008). Role conflict is defined as the stress associated with balancing two competing and often incompatible roles. Locke and Massengale's (1978) seminal work on role conflict in teacher-coaches differentiated between two types of role conflict: intrarole conflict and interrole conflict. Intrarole conflict arose when demands or expectations within a single role, such as the 
coaching role, were incompatible, whereas interrole conflict arose when demands of two or more roles, such as coaching and teaching, competed with one another and/or are incompatible. Sage (1987) added another construct known as work-family role conflict to describe the stress that arose from professional roles conflicting with familial roles. Clearly, SSTCs experience conflicting demands on their time, not only between teaching and coaching, but potentially between work and family as well.

There also appears to be a strong gender correlation as researchers found that females experience significantly higher levels of role conflict (Konukman et al., 2010; Bradford \& Keshock, 2009). The most prevalent contributor to role conflict, however, appeared to be role overload due to the long hours demanded of both roles. Role overload occurs "when the role expectations are too complex, too demanding, or too time consuming for the time and energy an individual has available" (Pitney, Stuart, \& Parker, 2008, p. 3).

Role conflict and role overload are primary contributors to burnout in teacher-coaches (L. A. Brown \& Roloff, 2011, 2015; Guest \& Conway, 2002; Spittle, Kremer, \& Sullivan, 2015). Maslach, Jackson, and Leiter (1996) popularized the term burnout to mean "a syndrome of emotional exhaustion (EE), depersonalization, and reduced personal accomplishment that can occur among individuals who do 'people work' of some kind" (p. 3). L. A. Brown and Roloff (2011) argued that the extra time required of coaching encroached upon the time teachers need to replenish lost resources (such as energy). Richards et al. (2014) found that core teachers experienced higher levels of role ambiguity, role overload, and possessed less resilience to burnout than PE teacher-coaches; the authors suggested that higher accountability in the classroom and less compatibility between teaching and coaching roles accounted for the burnout disparity. Furthermore, content teachers have frequently not received formal preparation in coaching (like their PE colleagues), which may contribute to burnout.

\section{Coping Mechanisms}

Despite the challenges of balancing dual roles, not all teacher-coaches who experience role conflict experience burnout. In fact, L. A. Brown and Roloff $(2011,2015)$ and O'Connor and MacDonald (2002) found that burnout levels in teacher-coaches were low to moderate. Researchers have found that to manage role conflict and avoid burnout, teacher-coaches often prioritized one role over the other through differential commitment or withdrew from one social role through role retreatism (L. A. Brown \& Roloff, 2011, 2015; Herbert, 2007; Millslagle \& Morley, 2004; Ressler, Richards, \& Wright, 2016). Drake and Herbert (2002) specifically investigated burnout in teacher-coaches and found that years of experience, point of time during the academic year, school context, and personal life all impacted their levels of stress and burnout. Participants experienced the highest level of stress during their induction years, at the peak of a coaching season, or when two coaching seasons overlapped; however, researchers found that through time management and organization skills, learning from mentors, and stress relieving techniques, teacher-coaches were able to avoid burnout despite role conflict.

\section{Methodology}

\section{Theoretical Framework}

The current research study was rooted in a constructionist epistemology as the social realities of SSTCs are relative to interpretation. We sought to understand a social phenomenon by gathering data from the context in which it already existed. We did not wish to manipulate the environment or determine causal relationships; hence, we used qualitative research methods to gather data from 
participants within the population they were seeking to understand: SSTCs. Subsequently, we gathered rich, descriptive data from SSTCs themselves, and together we constructed an interpretation of participants' experiences as SSTCs (Merriam, 2009; Silverman, 2010; Yin, 2008).

\section{Design and Participant Selection}

Employing a pragmatic approach, we sought the theoretical methodology most suitable to investigate the current research problem. Case study design affords a rich opportunity to illuminate the distinct characteristics of a phenomenon (Merriam, 2009; Silverman, 2010; Yin, 2008). Thus, we used a case study to conduct an in-depth investigation of the unique experiences of SSTCs over the course of their coaching seasons. Our goal was to capture the perceptions of SSTCs to describe their experiences with role conflict and role overload, and to identify coping mechanisms utilized to avoid burnout. Although we acknowledged the limitations of a qualitative approach in that it relies on the subjective nature of a researcher's interpretation of participants' experiences, we utilized researchbased strategies to strengthen the findings. Because of the in-depth nature of case study research, a small number of participants is typical.

The current research is grounded in prior literature on both role conflict and burnout in teachercoaches. Collection of data through multiple cases allowed a cross case synthesis of SSTCs' experiences (Yin, 2008). We further compared interview data with relevant school documents (teaching and coaching schedules, course syllabi, coaching manuals, playbooks, lesson plans, and teaching evaluations), participants' responses to interview questions, and their responses to the Maslach Burnout Inventory-Educators' Survey (MBI-ES). Data analysis was ongoing and extensive, and findings were continuously compared to prior literature on role conflict and burnout. Specifically, common themes and patterns in the data were compared to prior findings. Moreover, we employed member checks with participants to decrease researcher bias (Merriam, 2009; Silverman, 2010; Yin, 2008).

Participants were selected from a large school district in the southeastern United States. Purposeful sampling was used to identify potential participants who met the following selection criteria: high school social studies teacher, high school athletic coach of a fall sport, and employment in a public or private high school in the county under investigation (Patton, 2002). A recruitment flyer was sent to athletic directors within the county under investigation to disseminate to current coaches. Out of the five coaches who responded to the flyer, three met the selection criteria and provided informed consent. Thus, we conducted a multiple case study of three football SSTCs employed in different schools within a large southeastern county in the United States.

\section{Participant Descriptions}

To protect the identity of participants, pseudonyms have been given to both the teacher-coaches and their respective school sites. David teaches World Geography and Introduction to Law and coaches varsity football at Pine River. Pine River is a public high school serving over 3,000 students in a suburb of a large city. Approximately $34 \%$ of the student body is eligible for free and reduced lunch. Pine River is athletically competitive; the football team finished the 2014 season with a record of 84-0. David is in his sixth year as a SSTC, all of which have been served at Pine River. He teaches three 90-min classes a day with an average of 32 students per class. David currently serves as the varsity defensive line coach and the equipment manager. During the fall semester, he works approximately $78 \mathrm{hr}$ per week, $35 \%$ of which are spent in his teaching role (27.5 hr) and $65 \%$ of which are spent in his coaching role $(50.5 \mathrm{hr})$. David is married with two daughters, aged 6 and 3. 
Fred teaches economics and coaches varsity football at Walden, a small K-12 Christian private school. Walden serves approximately 450 high school students in a suburb of a large city. Walden is well respected for its rigorous academic curriculum and its Christian mission. The student body is predominantly Caucasian (90\%) and the cost of attendance is approximately $\$ 21,000$ per year. The football team finished the 2014 season with a record of 2-9-0. Fred has been a SSTC for a total of 18 years, 12 of which have been served at Walden. Fred is currently the head football coach and teaches a reduced load. He teaches four 55-min Economics classes and one period of study hall. The average number of students in his class is 18. During the fall semester, Fred works approximately 76.5 hr per week, $36 \%$ of which are spent in his teaching role $(27.5 \mathrm{hr})$ and $64 \%$ of which are served in his coaching role (49 hr). Fred is married with three children, aged 13, 11, and 8.

Jason teaches U.S. History and coaches varsity football at Northridge, a public high school in a suburb of a large city. Northridge serves over 3,000 students and is ethnically and socioeconomically diverse; approximately $65 \%$ of the study body is eligible for free and reduced lunch, classifying it as a Title I school. Northridge was extremely competitive athletically. The football team won two back-toback state titles in 2013 and 2014. Jason has been a teacher-coach for 20 years, 18 of which have been spent at Northridge. Jason teaches five 55-min classes of U.S. History and one section of guided study with an average class size of 31 . Currently, Jason is the varsity running back coach and the equipment manager. He also teaches driver's education. During the fall semester, Jason works approximately $68 \mathrm{hr}$ per week in his teacher-coach role, $48.5 \%$ of which are spent in his teaching role $(33 \mathrm{hr})$ and $51.5 \%$ of which are spent in his coaching role $(35 \mathrm{hr})$. He is married with two sons, both aged 6 . All three SSTCs spent more time coaching than teaching.

\section{Data Collection and Analysis}

Interviews were conducted at the beginning, middle, and end of each participant's coaching season. Each interview was conducted at the participant's school and lasted approximately $1 \mathrm{hr}$. Guiding questions were utilized to initiate conversation. Interview questions largely emerged from prior interview responses, survey, and documental data. After the initial interview, the primary researcher disseminated the MBI-ES, a questionnaire measuring participants' experienced level of burnout. Incorporating over 25 years of extensive research, the MBI-ES survey is a nationally recognized tool to measure burnout (Gold, 1984; Lahoz \& Mason, 1989; Maslach et al., 1996; Pierce \& Molloy, 1990). The MBI-ES addresses the following three burnout subscales: Emotional Exhaustion (feeling one's emotional resources are expended), Depersonalization (feeling distant from others), and Diminished Personal Accomplishment (a decline in feelings of job competence and/or achievement). On the survey, participants responded to 22 prompts such as "I feel used up at the end of the day" with responses that ranged from 0 (never occurred) to 6 (occurs every day). If a participant's score in a subcategory falls in the upper third of normal distribution, it indicates he is experiencing "high" burnout, the middle third indicates "moderate" burnout, and the bottom third indicates "low" burnout. In addition to survey data, documents were gathered throughout the research process such as teaching and coaching practice schedules, game schedules, coaching handbooks, lesson plans, syllabi, time logs, teaching evaluations, and scouting materials.

Throughout the research process, we used constant comparative analysis and cross-case synthesis to provide a rich, thorough account of both the unique and shared experiences of selected SSTCs (Merriam, 2009; Yin, 2008). Categories emerged inductively and were deductively revised as we continued to compare themes and patterns in the data. Interview data were transcribed, read several times, and coded by writing comments in the margins. We initially used open coding, in which they allowed any theme or pattern to emerge from the data. We then used analytical coding to group interview comments and survey responses that fit together. We subsequently wrote case memos for each SSTC that indicated emerging categories and identified areas to pursue in the next round of 
interviews. In addition, we wrote a cross-case memo in which they analyzed similarities in categories between participants.

Survey data were also analyzed prior to the mid-season interview to formulate interview questions about SSTCs' perceived experiences with burnout and coping mechanisms utilized to avoid it. After the MBI-ES was administered, we analyzed the results of the survey for each participant individually. Statistical analyses of the survey results were conducted by the online survey provider (Statistics Solutions) and delivered to us electronically along with the raw data set. Specifically, survey results indicated the experienced burnout level for each participant. SSTCs were categorized as experiencing a high degree of burnout, an average degree of burnout, or a low degree of burnout in each category. Although the MBI survey can be used to quantify an individual's experienced level of burnout, we used the data to qualitatively analyze the participant's perceptions of role conflict.

Throughout the research process, we compared categories within each participant's data separately; we then conducted a cross case analysis to compare and refine categories across participants. Categories were presented to participants for critique; their input led to modifications to increase accuracy. Each participant also reviewed his data during the final interview to further strengthen the findings. We decreased subjectivity through conducting multiple interviews over an extended period of time; using various data sources such interview, survey, and document data; and employing frequent member checks (Merriam, 2009; Silverman; 2010; Yin, 2008).

\section{Results}

\section{Role Conflict}

Participants experienced high levels of interrole conflict; occupying multiple roles competed for their time and energy. Specifically, participants endured high levels of teacher-coach role conflict due to contending professional roles and work-family role conflict as their familial roles competed with the professional duties and responsibilities. All three participants admitted that coaching responsibilities competed for their time and energy in the classroom. Similarly, their extensive workloads put serious strains on their personal relationships.

\section{David}

David stated that the hardest part of being a SSTC was balancing his time between roles. He lamented, “There just aren't enough hours in the day to get it all done." He admitted to cutting corners in the classroom to fulfill his coaching role.

There are some times during football when I have to give the kids a worksheet so I can get some stuff done. And that's not good but I ain't gonna get it done. And I try not to do that but sometimes I have to and a lot of times I do that-put a video in or give 'em a worksheet...

David described the intense pressure he felt as a football coach. "Either you do well and move on or you don't do well and you move on... If you do not win you will be replaced." Perhaps that partially explains why David spent more than twice as much time in his coaching role than his academic teaching role. He allotted only one planning period a week to lesson planning, while he spent four planning periods and at least $10 \mathrm{hr}$ each weekend preparing for football. He argued that practices conflicted with faculty and committee meetings, which he typically missed for football. David also admitted that he did not assign projects or papers due to his limited time to grade because of football demands. The only essays he graded were on exams, but he admitted, "They have a few sentences to impress me because I don't have time to read the whole thing..." 
Even more frustrating for David was that he earned less than minimum wage coaching; role undercompensation (see Conner, 2014) in his coaching role contributed to his level of role conflict. When asked why he became a coach, he remarked, "It's definitely not for the money (laughs)..." He explained that the booster club provided a small coaching stipend that helped a little, "but it's not as much as we deserve..." David also battled role misconception (see Conner, 2014) arising from the lack of respect colleagues afforded teacher-coaches. "A lot of times around the building there's a negative stereotype with coaches. They think we are a bunch of meatheads." He elaborated, "I mean people will say, 'Oh those football coaches, I mean they just don't have to go to department meetings...' And it's like yeah, I don't go to a 30-minute meeting sometimes 'cause I am here 'till 9 o'clock...” He further explained, "There is a jealousy factor there too. They just don't understand.” He provided the following example: "Like yesterday, I didn't get there until like 7 and some math teacher who teaches next to me said, "Well thanks for showing up." David stated that he stayed at school until 10 p.m. that night.

David had an especially hard time balancing his work and family roles this particular semester. His wife was in a horrific car accident at the beginning of the year and had to undergo multiple surgeries over several months. "My wife was hit by a drunk driver and nearly killed, which means I am $M r$. Mom." He added, "It's truly been a tough semester." In reflecting on his early years as a SSTC, he also indicated that it was hard to juggle teaching, coaching, his master's program, and a newborn. He reminisced, "We would just put Mary (his firstborn) in that little blue thing, and she would scream and we would work 'till like 11 o'clock every night."

\section{Fred}

Much like David, Fred found it extremely difficult to balance the roles of economics teacher and coach due to the competing demands. "It's like you have to be on all the time-you're in charge in the classroom and on the field so there is no down time. There is no time to recoup." Fred was the head football coach at his school, which meant he was constantly in the spotlight and the hot seat. The football team's success or failure began and ended with him. It's very hard... because, I mean, this is a job that requires an awful lot, as you know... a lot of time and a lot of energy..." Fred also spent more than twice as much time in his coaching role as compared to his teaching role. He spent his weekends and the majority of his planning periods each day preparing for football. Fred further admitted to relying heavily on current events, which reduced the amount of daily preparation required for his teaching role.

He recognized that "the community cares far more about what I do on Friday nights than about what I do in the classroom Tuesday morning." He added, "Certainly it's more exciting on Friday night, and they write articles in the newspaper about me about what happens on Friday night; they don't really care that they are studying aggregate supply." Winning football games, however, required an extensive amount of time and energy — some of which was sacrificed from his teaching role. Consequently, losing games increased he feelings of role incompetence (Pitney et al., 2008). "The football season has been challenging... we have only won two games..." He further elaborated, "A tough football season is stressful... the stress of being an in-season football coach during a season that is not very successful on the outside, on paper, is frustrating..." Fred also felt that he was frequently battling perceived misconceptions of SSTCs, which increase his feelings of role conflict.

Sometimes, I feel like my academic colleagues think that we are just stereotypical football coaches... who probably was a meathead, ya know? I think I surprise a lot of people when I can put a coherent sentence together... And that's not who we are; I mean everybody on our staff has advanced degrees and is professional, and accomplished, and well-educated... we just happen to also coach football. 
Unlike David, Fred felt better compensated for his roles but noted that SSTCs still made far less than they deserved. He elaborated,

You're just praying that your car doesn't break down. Ya know, or something else. And that's a huge challenge... we live paycheck to paycheck and we don't have a very big rainy day fund, and we are a broken transmission or a hole in the roof away from being in some trouble...

Finances were tight, but the hardest part for Fred was balancing his work and family roles. When asked to describe his personal life, he remarked,

I'm never at home and I don't get to see my wife... I want to be the best that I can be for these kids, but now my own kids need me... and I realize that I spend more time with other people's kids than I do my own children and that's not okay with me...My son got cut from the basketball team this year and I feel responsible for that because I wasn't around to shoot with him or help him...

Fred's children, who were older than both Jason and David's, participated in extracurricular activities of their own, which he frequently missed due to his coaching responsibilities. He later lamented, "My son had his first two wrestling matches of his life today, and I was on the practice field..."

Even when he was home, Fred felt distracted by his work roles. "My time at home is very, very important. But I also, I've got grading to do... so sometimes I get home and I don't feel like I'm exactly home, 'cause I'm grading at the kitchen table..." Maintaining relationships outside of school proved to be the biggest challenge to Fred.

\section{Jason}

Like David and Fred, Jason felt overwhelmed by competing teaching and coaching demands. In describing how he balanced the roles, he remarked, "Sometimes I feel like a chicken running around with its head cut off... other times like I am just going through the motions." He described,

It's like giving a business speech, giving a presentation or a sales pitch all day... not that I lecture all day, but I'm in charge all day of whoever it is, kids in this class, that class, this group on the field; so you gotta be "on" all day long and that is physically and mentally exhausting...

Jason believed that working in a Title I school was extremely rewarding, but he also argued it was enormously challenging. For example, more of his students appeared to struggle academically, which required him to accommodate by spending more time in his teaching role.

So many of these kids, I mean $65 \%$ of them are on free and reduced lunch, which means they are poor, which a lot of times means education is not reinforced; they don't have a dad and ya know that's a huge obstacle.

Jason described the difficultly of completing his teaching duties: "There is so much lesson planning, so much grading... I probably got 155 students right now." He compensated by not assigning papers or projects. Other than quizzes and exams, he collected only two assignments per unit and graded both for completion. He felt justified in such prioritization because of the intense pressures placed on coaches. "Football is a big deal here... we are expected to win." He elaborated, "If we weren't winning they would probably start looking for some new coaches." 
What frustrated Jason even more was the low compensation he received for the hours he worked. He stated, "I mean you don't get paid enough... I think my JV (junior varsity) stipend was $\$ 327$ dollars a month... a month!" When asked why he taught driver's education, he stated, "I'm doing that so we can pay our bills... I haven't gotten a raise in 5 years... And the way I make up for it is by busting my butt teaching driver's ed all summer..." Jason also described stress of "living paycheck to paycheck" and the difficulty of saving for his sons' future college expenses. "You're not making enough to justify being gone from your children that long," he explained.

The biggest source of stress for Jason was not finances, but rather work-family role conflict. He lamented, "When I come home I mean I've got nothing left hardly... for my kids..." He bemoaned, "You sometimes get to the point where you're like, I'm helping raise all these other kids, but what about mine?" Consequently, Jason had recently decided to decrease his weekend coaching responsibilities because he said it was tearing his family apart.

He remarked, "My schedule was so bad that my kid actually went to me enough times and started giving me the ya know, "Daddy when are we gonna see you?" kinda thing, and it was just breaking my heart..."

Jason explained, "The varsity coaches usually meet on Sundays, and I stopped doing that last year." In fact, at the end of the study, Jason announced that he was leaving Northridge after 18 years to be closer to home.

\section{Role Overload}

Unable to recoup lost energy and combat role conflict, participants frequently felt overextended and drained. Role overload, sometimes referred to as role strain, occurs when the role expectations are too complex, too demanding, or too time consuming for the time and energy one has available (L. A. Brown \& Roloff, 2011; Pitney et al., 2008). Harrington (1994) argued that working an excess of 48-56 $\mathrm{hr} / \mathrm{wk}$ is harmful to one's health. Health problems are exacerbated by jobs that require work done at home. According to Fleck (2009), the average teacher worked $53.14 \mathrm{hr} / \mathrm{wk}$, which is $13 \mathrm{hr} / \mathrm{wk}$ more than the average employee (40.25). SSTCs, however, appear to work far more than even the average teacher. In fact, all three participants worked well over the teacher average of $53.14 \mathrm{hr} / \mathrm{wk}$ during football season, with Jason averaging 68, Fred 76.5, and David $78 \mathrm{hr} / \mathrm{wk}$. These long hours took their toll on SSTCs both mentally and physically.

\section{David}

David stated that he worked about $78 \mathrm{hr} / \mathrm{wk}$ during football season, about 28 of which went to teaching. Outside of traditional teaching and varsity coaching responsibilities, he noted that he was required to attend all $\mathrm{JV}$ football games and scout opponents by watching and grading film. $\mathrm{He}$ attended workouts and coaches' meetings on Saturdays and Sundays. "I also get the wonderful title of equipment coach...which means you manage 150 players' worth of equipment. So you got to do all that laundry... I'm talking laundry!" David said it took him 4-6 hr/wk to complete his "housekeeping" duties. David frequently reported feelings of exhaustion, fatigue, and weariness. He remarked,

There are days when I wake up and like yesterday, I didn't know how I was going to do a 20hour day. I took my blanket and threw it into the back of the truck 'cause I thought for sure I was just gonna go to sleep during my planning period.

Role overload exacerbated feelings of role conflict David experienced. 


\section{Fred}

Fred also spent approximately $77 \mathrm{hr} / \mathrm{wk}$ working, approximately 28 of which were spent in his coaching role. He elaborated that coaches worked from noon until 10 p.m. on Sundays watching films and game planning for the upcoming week. Game days appeared to be his longest days. $\mathrm{He}$ remarked,

Fridays, if we are on the road, we could be gone 'till the wee hours of the morning, so that's another 15-, 16-, 17-hour day... we leave at 2:15 p.m. and I expect we won't be back until after midnight. So it's a long day...

Fred frequently described the feeling of being overextended and the intense demands placed on being a head football coach at a prestigious private school. He said, "As the head football coach at Walden, I am supposed to outline, implement, and communicate a vision for our football program that is in line with the school's mission." He also described writing and maintaining the coaches' handbook, assisting in the hiring process, and attending professional development conferences. Fred explained that head football coach was a 12 -month commitment; summer vacation, he argued, was an illusion. Fred complained that the long hours required of dual roles prevented him from having much of a life outside of work. He bemoaned,

I don't seem to have much going on outside of my job... when I'm not here I like to be with my family. I'm not a golfer... I love to play golf, but I don't have the time; I'm not a fisherman... I love to fish, but I don't have time...

Role overload appeared to be most severe towards the end of the season as energy and stamina waned.

\section{Jason}

In his SSTC role, Jason stated that he worked approximately $68 \mathrm{hr} / \mathrm{wk}$, approximately 33 of which were spent in his teaching role. Though driver's education hours were hard to track because they fluctuated by demand, there were some weeks where he added 10-12 hr in his driver educator role. Jason lamented, "I've done this schedule for about 5 years, and it's too much... you get to the point where you feel like you can't do anything really well because you are so overspread..."

In addition to teaching and coaching responsibilities, Jason participated in additional academic responsibilities as a JV coach. For example, he participated in weekend academic "boot camps" to prepare students for state and district exams and/or to help students recover from failed courses through "credit recovery." He noted,

I am the running backs coach. I am also, all coaches are also JV coaches, so we coach Thursday night games and of course Friday night games, and we all do the out of season stuff... And you'd think that they wouldn't make the guy who has been here for 17 years do the laundry...

Duties of the equipment manager included keeping track of the footballs, helmets, pads, and uniforms-uniforms that he had to wash weekly. He explained that all coaches were also expected to fundraise, supervise study hall, and attend all coaches' meetings; they were also assigned a "latenight duty" once a week to clear the campus. He also organized picture day and snacks for summer workouts. Jason elaborated that both football and driver's education were yearlong roles. "For me there's not really an off-season." 


\section{Burnout}

Prior researchers suggested that role conflict and role overload are frequently associated with increased levels of burnout in teacher-coaches (Pitney et al., 2008). Following the first interview, each participant took the MBI-ES, a nationally recognized assessment of educators' experienced level of burnout.

Results of the MBI-ES indicate that participants avoided high levels of burnout over the course of their coaching seasons despite high levels of role conflict. All three SSTCs scored low in depersonalization and diminished personal accomplishment (PA). Jason and David indicated a low level of EE, whereas Fred exuded a moderate frequency of EE. Of all burnout indicators, EE levels were the most acute for all three participants. When asked to reflect on their survey results, each participant provided examples of EE. David explained, "For me, this semester taking care of them two (points to kids), having a wife that is basically paralyzed... and teaching and coaching... that was emotionally draining." He elaborated that most of his exhaustion is associated with the long hours, stating that at times he feels as if "there is no end in sight." Similarly, Jason lamented about the feeling of being used up.

A lot of times at the end of the day I don't have a lot left... I love working with kids and people but it is emotionally draining and it just wears you out, and I don't know if it is because I am older, or because I have 6-year-olds, but I am tired.

Fred explained that his exhaustion largely stemmed from the

hours... I mean you gotta be "on" like the entire time; when you're in the classroom or on the practice field, particularly in the classroom, you gotta be in charge and then I get to the football field and I'm in charge there too.

Fred described coaching as a roller coaster of emotions, stating that

Every Friday night is an emotional rollercoaster for me and for my other coaches and kids... and I know it's just a game but it's not just a game for us. I mean we pour everything into this... I mean we get into the heat of battle on Friday night and especially this year when we are killing ourselves trying to be successful and we're not, it's very emotional, it's very difficult... and on Friday night at about 10 o'clock I'm just so exhausted that I can't speak, and it's difficult.

Each SSTC acknowledged that role overload and work-family role conflict contributed heavily to feelings of EE. Participants further noted severe time constraints and elevated levels of stress during football season. Jason emphasized that role under-compensation (see Conner, 2014) also contributed to his feelings of burnout. Participants' argued that their perceived levels of burnout increased when the football team lost and towards the end of the regular season as energy waned. Fred, the only coach who endured a losing season, scored the highest in all burnout categories; consequently, there appears to be a connection between losing games and feelings of EE burnout.

\section{Coping Mechanisms}

Despite experiencing role conflict and role overload, participants were able to manage stress to prevent high levels of burnout. SSTCs explained that a combination of personal characteristics, environmental factors, and personal coping mechanisms aided them in maintaining their stamina. 


\section{Personal characteristics}

All participants perceived they possessed a high level of commitment to both teaching and coaching. The SSTCs believed coaching made them better teachers and vice versa. David further explained, "I don't want to be defined by coaching. If I quit coaching tomorrow, I would be okay; the sun would still come up. I really enjoy teaching as well.” Formal teaching evaluations demonstrated that all three participants met or exceeded administrators' expectations in the classroom. All participants experienced success in both professional roles. For example, each coach had won state championships.

Professional experience similarly reduced their levels of role conflict and burnout. Each SSTC admitted that his ability to balance dual roles became easier as his career progressed. David argued he learned how to prioritize tasks and pace himself. "I think the more experience you get doing a job you become more efficient at doing it." They admitted that such efficiency was partly a result of being able to reuse and tweak teaching and coaching materials each year. Each SSTC was also extremely organized. In particular, they each stressed using time wisely, especially during planning periods, to avoid taking work home with them. Fred advised, “Use your planning periods. Don't sit up there and look at ESPN or fill out your tournament bracket. Try to take as little school work home with you as possible." SSTCs further emphasized the importance of establishing schedules, routines, and grading systems to maximize efficiency. Moreover, each SSTC argued that using summers to plan for the upcoming school year was an essential organizational strategy to reduce role overload during football season.

\section{Environmental factors}

Each SSTC emphasized the importance of community support to his ability to manage dual roles effectively. In particular, participants stressed administrative support from principals and coaching staffs. Additionally, participants acknowledged administrative accommodations that aided them in their ability to reduce role conflict. At each participant's respective school, head football coaches received reduced teaching loads in the form of two planning periods. Likewise, weight training was embedded into most players' schedules, which reduced the amount of extra time required of SSTCs. All three participants enjoyed reduced teaching duties. Moreover, David and Jason both argued that having last period planning was an important accommodation for which they both negotiated. Jason and Fred also admitted that monitoring one period of study hall rather than teaching an additional social studies class lessened their grading responsibilities. Lastly, each SSTC believed that his ability to teach the same subject every year reduced his stress because he was able to modify course materials. Community support was particularly important to participants early in their careers. For example, each SSTC specifically discussed the significance of mentors in learning to manage dual roles. Such mentorship decreased feelings of role incompetence experienced early in each participant's career (Pitney et al., 2008).

\section{Personal releases}

Each SSTC remarked that "down time" or personal releases were imperative tools to manage stress. Personal releases are defined as individual stress relievers utilized by SSTCs to manage role conflict and avoid burnout. David explained, "I think getting away is the biggest thing-having something to do outside of school..." Participants argued that a teacher-coach must "know when to take breaks" and be able to pace himself. David argued that football season was "a marathon, not a sprint." Fred stressed the importance of his faith, music, and exercise. Jason also highlighted exercise, stating, "I exercise like a mad man so I think that helps... exercise gives you energy, you release endorphins." Although his type of personal release varied, each SSTC articulated the importance of mental and physical breaks from the stress of the job. Fred summarized, "There's got to be some boundaries. At some point you got to put it to bed... otherwise the job will run you into the ground; you will burn out fast..." 


\section{Discussion}

This research study explores the unique experiences of the social studies teacher-coach. It provides SSTCs a voice to explain the challenge of balancing dual roles simultaneously. Participants were able to describe for themselves the personal and environmental factors that helped them cope with role conflict. These findings build upon current research in role conflict and burnout and highlight the unique stressors that SSTCs endure. Most importantly, the current study raises serious concerns about the unequal rewards systems that exist for SSTCs in the sports subculture within our educational system.

As prior research indicates, the SSTCs in this study were the most common content teacher-coaches at each school site (Miller et al., 2006; Rodgers, 2013; Stacy, 2014). Social studies departments were predominantly male as were teacher-coaches in each school (A. Brown, 2012a; Busey \& Waters, 2016; A. Brown \& Sieben, 2013; Chiodo et al., 2002; Fitchett, 2010; Weller, 2002). Participants acknowledged the trend for male social studies teachers to coach; each of them explained that they were specifically hired to be SSTCs. Moreover, Jason and Fred stated that their first jobs were contingent upon coaching multiple sports. David explained that he had replaced a SSTC when he was hired and that when he left, he would be replaced by another SSTC.

Each participant experienced role misconception (see Conner, 2014) as he felt he had to battle negative perceptions of SSTCs from noncoaching teachers. Some of the participants' responses seemed to reinforce stereotypes of coaches as they talked about shortcuts in teaching to meet coaching demands. Like the coaches in studies conducted by Rodgers (2013) and A. Brown (2012b), participants believed that the media and broader educational community perceived them to be meatheads. They expressed volatile relationships with non-coaching colleagues. They reported feelings of isolation and misunderstanding. They felt underpaid and unappreciated for the time and energy it took to fulfill their dual roles.

Like prior studies of teacher-coach role conflict, all three participants experienced intense and pervasive role conflict resulting from competing demands of teaching and coaching (A. Brown, 2012b; Konukman et al., 2010; O'Connor \& MacDonald, 2002; Richards \& Templin, 2012). Specifically, the time demands required of occupying the role of SSTC were overwhelming and resulted in role overload and EE (L. A. Brown \& Roloff, 2011; Pitney, et al., 2008). During football season, participants worked an excess of $70 \mathrm{hr} / \mathrm{wk}$-far more than the average teacher who worked $53 \mathrm{hr} / \mathrm{wk}$ (Bill and Melinda Gates Foundation, 2012). In addition to conflict arising due to competing professional roles, each coach also struggled to balance their work and familial roles (Graham \& Dixon, 2017; Ryan \& Sagas, 2011). They indicated feelings of guilt and remorse for spending more time with "other people's kids" than their own. They noted the strain that the time away from home placed on the relationships with their wives, their friends, and their children.

Despite the intense examples of role conflict and role overload experienced by each participant, they all avoided high levels of burnout. These results provide serious recommendations for how social studies teachers may avoid burnout in an extremely demanding job. Participants recommend that potential SSTCs evaluate their commitment to each role and carefully assess whether they have the work ethic and resiliency to overcome long hours and inadequate pay. They stress the importance of finding several mentors to support them in each role and provide resources, advice, and guidance. Participants emphasize the need for organization through time management, systems, routines, and procedures that increase efficiency. They highlight the importance of personal releases or coping mechanisms to reduce stress such as exercise, music, prayer, or family time. Lastly, participants recommend being honest and vocal about their needs with administrators, colleagues, parents, and coaching staffs. They believe it is important to ask for help or take a break when feeling overwhelmed. 
The suggestions provided by participants are supported by prior findings. Ryan (2008) found that teacher-coaches who demonstrated a role preference imbalance demonstrated a higher level of role conflict. Teacher-coaches in a case study conducted by Drake and Herbert (2002) also relied on personal releases, organizational skills, and mentors to avoid burnout. Pitney et al. (2008) found that teachers who were more vocal about their needs and were proactive with administrators suffered less role strain.

As prior researchers conclude, participants often coped with role conflict by withdrawal from their teaching role during coaching season (Herbert, 2007; Ressler, et al., 2016; Millslagle \& Morley, 2004). Participants admitted to spending significantly more time in their coaching role. Sometimes they relied more heavily on teacher-centered strategies when pressed for time. Instead of criticizing them for this fact; however, it is critical to consider why they retreated.

Numerous studies suggest that role retreatism toward the coaching results from an unequal rewards system favoring the coaching role (Konukman et al., 2010; Kwon et al., 2010; O'Connor \& MacDonald, 2002; Richards \& Templin, 2012). In the current study, participants perceived that community members cared more about their performance on the field than they did about their performance in the classroom. They were publicly recognized and praised for success in their coaching role; however, no one celebrated Jason for his students' improved test scores in history. Corroborating results from Ressler et al. (2016), teacher-coaches are often praised financially and publicly for their accomplishments in coaching but ignored for good teaching. Each participant had won awards and state titles for their efforts to win football games.

Similarly, participants felt there was more opportunity for job advancement and promotion in coaching than in education. Kwon et al. (2010) suggested that the higher accountability in coaching and pressure to win contributes to PE teacher-coaches identifying more with their coaching role. In the current study, two participants perceived that their job security was tied to their coaching performance. Moreover, each SSTC received a rating of proficient or exemplary on every teaching indicator on his state teaching evaluations. Their evaluations suggest that their retreatism was either accepted by administrators, or that it was not perceived to negatively impact their students in the classroom.

In addition to an unequal rewards system, Konukman et al. (2010) found that faulty assumptions and the oversimplification of occupational roles by administrators exacerbated role conflict in PETCs. Similarly, administrators often underestimated the time required to perform each role. However, Pitney et al. (2008) established that teachers who perceived more administrative and social support indicated lower levels of role strain. All three participants in the current study successfully avoided burnout and felt adequately supported by administrators.

Thus, this research study not only has implications for the role SSTCs may take to avoid burnout, but also how administrators and school systems at large may better support SSTCs. Avoid hiring social studies teachers' contingent on their willingness to coach. Refrain from disproportionately assigning social studies teachers multiple coaching assignments. Hire candidates who demonstrate a strong commitment to both roles. Be honest and explicit during the hiring process about the time commitment to each role. Provide an equal rewards system for teaching and coaching success. Hold SSTCs equally accountable for their dual roles. Be explicit and realistic about demands placed on SSTCs. Provide adequate resources and support systems. Reduce the extra time required of SSTCs when possible by accommodating their teaching or coaching loads. 
The current study provides suggestions for both SSTCs and administrators to help alleviate the conflict associated with occupying dual roles. More research is needed to explore the administrative hiring practices for social studies teachers, role retreatism in SSTCs, and the unequal rewards system for SSTCs that exists in the American educational sports subculture. More importantly, researchers need to examine the growing sport culture in the educational system positively and negatively impacts students. Fouts (1989) and Van Deraa \& Schug (1993) were the last to investigate students' perceptions of SSTCs classrooms and their results, though somewhat mixed, suggest that SSTCs' classrooms were not significantly different from those of non-SSTCs. Yet SSTCs continue to be criticized for their perceived teaching "ineffectiveness."

One limitation of the current study is the lack of female voices. It is important to note that no females volunteered for the study; in analyzing the demographic composition of the schools, there were far fewer female SSTCs at each site. Several prior studies demonstrate the strong relationship between gender, teaching social studies, and coaching (A. Brown, 2012a; A. Brown \& Sieben, 2013; Fitchett, 2010; Stacy, 2014); future research is needed to explore the reasons for the connection. Moreover, prior research on role conflict suggests that females indicate higher levels of role conflict as compared to their male counterparts (Bradford \& Keshock, 2009); such disparities warrant investigation to determine what additional supports female may need to successfully balance dual roles.

Another limitation of this study is that results are not generalizable to all SSTCs as each teachercoaches' experience is invariably dependent upon context. To gain an in-depth understanding of each participants' experience, a small number of participants was desired to provide as detailed depiction of their daily lives as possible. The use of multiple cases, various sources of data, and the employment of frequent member checks decreased such limitations. Although results may not be generalizable, the shared experiences of participants from different school contexts illuminate similar challenges to managing role conflict.

If balancing dual roles of teacher and coach is associated with heightened levels of role conflict, burnout, and teacher turnover, then it is imperative to adequately support teacher-coaches. Moreover, because social studies teachers are disproportionately the most common content teachercoaches, researchers must continue to explore ways to alleviate role conflict in SSTCs-especially because SSTCs are less likely than PE teacher-coaches to receive formal preparation in coaching (Camiré et al., 2017). Finally, instead of continuously criticizing SSTCs for their role retreatism, the educational community should focus on why SSTCs retreat and how to assist them in reducing such prioritization. Educational researchers might begin by investigating the administrative hiring practices of social studies teachers, the unequal rewards system of SSTCs, and the sports subculture permeating American schools. An optimal way to help social studies students is to support social studies teachers-many of whom are also athletic coaches.

\section{References}

Bill and Melinda Gates Foundation. (2012). Primary sources: 2012: America's teachers on the teaching profession. Retrieved from http://www.scholastic.com/primarysources/pdfs/Gates2012_full.pdf

Bradford, S. H., \& Keshock, C. M. (2009, March). Female coaches and job stress: A review of the literature. College Student Journal, 43, 196-200.

Brown, A. (2012a). The gender integration of a core are teacher/athletic coach in the rural Southeastern United States. Sport, Education and Society, 17, 627-646. 
Brown, A. (2012b). The occupational socialization of novice, core content area teacher/athletic coaches (Doctoral dissertation). College of Education, University of Alabama, Tuscaloosa, AL.

Brown, A., \& Sieben, N. (2013, Summer). The elephant in the classroom: Examining the influence of athletic coaching on secondary preservice teachers. Teacher Education Quarterly, 40, 107122 .

Brown, L. A., \& Roloff, M. E. (2011, December). Extra-role time, burnout, and commitment: The power of promises kept. Business Communication Quarterly, 74, 450-474.

Brown, L. A., \& Roloff, M. E. (2015). Organizational citizenship behavior, organizational communication, and burnout: The buffering role of perceived organizational support and psychological contracts. Communication Quarterly, 63, 384-404.

Busey, C. L., \& Waters, S. (2016). Who are we? The demographic and professional identity of social studies teacher educators. The Journal of Social Studies Research, 40, 71-83.

Camiré, M., Rocchi, M., \& Kendellen, K. (2017). A comparative analysis of physical education and non-physical education teachers who coach high school sport teams. International Journal of Sports Science \& Coaching, 12, 557-564.

Chiodo, J. J., Martin, L. A., \& Rowan, S. L. (2002). Coaching and teaching social studies: The perceptions of preservice teachers. Journal of Social Studies Research, 26, 10-19.

Conner, C. (2014). Acknowledging the elephant in the room: A multiple-case study exploring the experiences of social studies-teacher coaches (Doctoral dissertation). College of Education, Georgia State University, Atlanta, GA.

Drake, D., \& Herbert, E. P. (2002). Perceptions of occupational stress and strategies for avoiding burnout: Case studies of two female teacher-coaches. Physical Educator, 59, 170.

Egalite, A. J., Bowen, D. H., \& Trivitt, J. R. (2015). Do teacher-coaches make the cut? The effectiveness of athletic coaches as math and reading teachers. Education Policy Analysis Archives, 23. doi:10.14507/epaa.v23.1901

Fitchett, P. G. (2010). A profile of twenty-first century secondary social studies teachers. Journal of Social Studies Research, 34, 229-265.

Fouts, J. T. (1989). Coaching athletics and the social studies classroom. Social Education, 53, 117122.

Gold, Y. (1984). The factorial validity of the Maslach Burnout Inventory in a sample of California elementary and junior high school classroom teachers. Educational and Psychological Measurement, 44, 1009-1016.

Graham, J. A., \& Dixon, M. A. (2017). Work-family balance among coach-fathers: A qualitative examination of enrichment, conflict, and role management strategies. Journal of Sport Management, 31, 288-305.

Guest, D., \& Conway, N. (2002). Communicating the psychological contract: An employer perspective. Human Resource Management Journal, 12, 22-38.

Ha, J., Hums, M. A., \& Greenwell, T. (2011). Dual role of physical education teacher athletic directors in Korean secondary schools. Physical Educator, 68, 221-233.

Herbert, M. (2007). Physical educator/coach role conflict: A study of male high school basketball coaches in metropolitan area (Doctoral Dissertation). Retrieved from ProQuest. (ProQuest ID 3298188) 
Konukman, F., Agbuga, B., Erdogan, S., Zorba, E., Demirhan, G., \& Yilmaz, I. (2010). Teacher coach role conflict in school-based physical education in USA: A literature review and suggestions for the future. Biomedical Human Kinetics, 2, 19-24.

Kwon, H. H., Pyun, D. Y., \& Kim, M. (2010). Perceived leadership behavior of physical education teacher-coaches: When they teach vs. when they coach. Journal of Teaching in Physical Education, 29, 131-145.

Lahoz, M. R., \& Mason, H. L. (1989). Maslach Burnout Inventory: Factor structures and norms for USA pharmacists. Psychological Reports, 64, 1059-1063.

Locke, L. F., \& Massengale, J. D. (1978). Role conflict in teacher/coaches. Research Quarterly, 49, $162-174$.

Maslach, C., Jackson, S. E., \&. Leiter, M. P. (1996). MBI manual (3rd ed.). Mountain View, CA: CPP.

Merriam, S. B. (2009). Qualitative research: A guide to design and implementation. San Francisco, CA: Wiley, John \& Sons.

Miller, G. A., Lutz, R., Shim, J., Fredenburg, K., \& Miller, J. (2006). A national study of nonrenewal in high school coaching. Journal of Physical Education, Recreation \& Dance, 77, 40-45.

Millslagle, D., \& Morley, L. (2004). Investigation of role retreatism in the teacher/coach. Physical Educator, 61, 120-130.

National Association for Sport and Physical Education. (2008). National coaching report: The state of coaching in the U.S. Reston, VA: Author.

O'Connor, A., \& Macdonald, D. (2002). Up close and personal on physical education teachers' identity: Is conflict an issue? Sport, Education and Society, 7, 37-54.

Patton, M. (2002). Qualitative research and evaluation methods (3rd ed.). Thousand Oaks, CA: Sage.

Pierce, C. M. B., \& Molloy, G. N. (1990). Psychological and biographical differences between secondary school teachers experiencing high and low levels of burnout. British Journal of Educational Psychology, 60, 37-51.

Pitney, W. A., Stuart, M. E., \& Parker, J. (2008). Role strain among dual position physical educators and athletic trainers working in the high school setting. Physical Educator, 65, 157-168.

Ressler, J. D., Richards, A. R., \& Wright, P. M. (2016). The sociopolitics of sport, physical education, and school health in the United States. Journal International Journal of Sport Policy and Politics, 8, 745-748.

Richards, A. K. R., \& Templin, T. J. (2012). Toward a multidimensional perspective on teacher-coach role conflict. Quest, 64, 164-176.

Richards, A. K. R., Templin, T. J., Levesque-Bristol, C., \& Blankenship, B. T. (2014). Understanding differences in role stressors, resilience, and burnout in teacher/coaches and non-coaching teachers. Journal of Teaching in Physical Education, 33, 383-402. doi: 10.1123/jtpe.20130159

Rodgers, J.B. (2013). An examination of the relationship between football coaches and the teaching of social studies in the state of Texas (Doctoral dissertation). Retrieved from ProQuest. (ProQuest ID 3593330)

Ryan, T. D. (2008). Antecedents for interrole conflict in the high school teacher/coach. Physical Educator, 65, 58-67.

Ryan, T. D., \& Sagas, M. (2011). Coaching and family: The beneficial effects of multiple role membership. Team Performance Management: An International Journal, 17, 168-186. 
Sage, G. H. (1987). The social world of high school athletic coaches: Multiple role demands and their consequences. Sociology of Sport Journal, 4, 213-228.

Shuttlesworth, B., \& Edgington, W. (2005, May). Preparing non-historians to teach history: The coaching history playbook. Perspectives on History. Retrieved from https://www.historians.org/publications-and-directories/perspectives-on-history/may2005/preparing-non-historians-to-teach-history-the-coaching-history-playbook

Silverman, D. (2010). Doing qualitative research (3rd ed.). London, United Kingdom: Sage Publications.

Spittle, M., Kremer, P., \& Sullivan, S. (2015). Burnout in secondary school physical education teaching. Physical Education and Sport, 13, 33-43.

Stacy, M. (2014). The historical origins of social studies teacher as athletic coach. American Educational History Journal, 41, 301-312.

Van Deraa, A., \& Schug, M. C. (1993). Coaching athletics and the social studies classroom: A replication study. Social Education, 57, 116-118.

Weller, K. E. (2002). Do pre-service secondary geography teachers want to be teachers or coaches? Journal of Geography, 101, 131-136.

Yin, R. K. (2008). Case study research: Design and methods (4th ed.). Thousand Oaks, CA: Sage.

The Journal of Educational Research and Practice provides a forum for studies and dialogue that allows readers to better develop social change in the field of education and learning. Journal content may focus on educational issues of all ages and in all settings. It also presents peer-reviewed commentaries, book reviews, interviews of prominent individuals, and additional content. The objectives: We publish research and related content that examines current relevant educational issues and processes aimed at presenting readers with knowledge and showing how that knowledge can be used to impact social change in educational or learning environments. Additional content provides an opportunity for scholarly and professional dialogue regarding that content's usefulness in expanding the body of scholarly knowledge and increasing readers' effectiveness as educators. The journal also focuses on facilitating the activities of both researcher-practitioners and practitioner-researchers, providing optimal opportunities for interdisciplinary and collaborative thought through blogging and other communications.

Walden University Publishing: http://www.publishing.waldenu.edu 